\title{
Recommendation for optimal management of severe refractory asthma
}

\author{
This article was published in the following Dove Press journal: \\ Journal of Asthma and Allergy \\ 2I July 2010 \\ Number of times this article has been viewed
}

\author{
Jaymin B Morjaria' \\ Riccardo Polosa ${ }^{2}$ \\ 'Department of IIR, University of \\ Southampton, Southampton, UK; \\ ${ }^{2}$ Dipartimento di Medicina Interna e \\ Specialistica, University of Catania, \\ Catania, Italy
}

\begin{abstract}
Patients whose asthma is not adequately controlled despite treatment with a combination of high dose inhaled corticosteroids and long-acting bronchodilators pose a major clinical challenge and an important health care problem. Patients with severe refractory disease often require regular oral corticosteroid use with an increased risk of steroid-related adverse events. Alternatively, immunomodulatory and biologic therapies may be considered, but they show wide variation in efficacy across studies thus limiting their generalizability. Managing asthma that is refractory to standard treatment requires a systematic approach to evaluate adherence, ensure a correct diagnosis, and identify coexisting disorders and trigger factors. In future, phenotyping of patients with severe refractory asthma will also become an important element of this systematic approach, because it could be of help in guiding and tailoring treatments. Here, we propose a pragmatic management approach in diagnosing and treating this challenging subset of asthmatic patients.
\end{abstract}

Keywords: severe asthma, corticosteroids, immunological modifiers, steroid-sparing, anti-TNF- $\alpha$ drugs, omalizumab, mepolizumab, daclizumab, bronchial thermoplasty

\section{Introduction}

Asthma is a common chronic inflammatory disorder of the airways characterized by bronchial hyperresponsiveness (BHR), reversible airflow limitation, and recurrent episodes of wheezing, shortness of breath, chest tightness, and cough. Asthma is a complex syndrome with many clinical and inflammatory phenotypes. ${ }^{1}$ Various factors like the environment, genetics, levels of hygiene, and atopic status play a role in the development and progression of asthma phenotypes. Most patients with asthma have mild-to-moderate disease and can be easily controlled by regular use of inhaled corticosteroids (ICS) combined with short-acting inhaled $\beta_{2}$-agonists for relief of symptoms. However, for some patients, asthma continues to be poorly controlled in terms of ongoing symptoms, frequent exacerbations, persistent and variable airway obstruction, and frequent requirement for $\beta_{2}$-agonists despite aggressive treatment. Severe or refractory disease remains a frustrating problem for both patients and the clinicians treating them with disproportionately high health-related costs. ${ }^{2-5}$ A number of clinical definitions have been proposed through national and international guidelines, working groups, which incorporate lung function, exacerbations, and use of high-dose corticosteroids. ${ }^{2,6-8}$ Of note, is that all these various criteria/guidelines are applicable when patients have had adherence and exacerbations fully addressed. ${ }^{9,10}$ Many different terms have been used to describe this group of patients with persisting symptoms and frequent exacerbations despite being treated with high-intensity treatment for asthma.
Correspondence: Jaymin B Morjaria Department of IIR, Mailpoint 8I0, South Academic Block, University of Southampton, Tremona Rd, Southampton SOI6 6YD, UK Fax +44 238077077| Email jbm@soton.ac.uk 
The term problematic severe asthma should be used for all patients who remain uncontrolled despite prescription of high-intensity asthma treatment. ${ }^{11}$ Apart from patients with true severe refractory asthma (SRA), this group also includes patients with "difficult asthma," that is uncontrolled asthma for reasons such as persistently poor compliance, psychosocial factors, or persistent environmental exposure to allergens or toxic substances. It also includes patients who have mild - moderate disease that is aggravated by comorbidities such as chronic rhinosinusitis, reflux disease, or obesity. The term severe refractory asthma should be reserved for those patients with severe disease who have been under the care of an asthma specialist for $>6$ months, and still have poor asthma control or frequent exacerbations despite taking high-dose ICS combined with long-acting $\beta_{2}$-agonists (LABA) or any other controller medication or for those who can only maintain adequate control by taking oral corticosteroids (OCSs) on a continuous basis, and are thereby at risk of serious adverse effects.

Current asthma guidelines offer little alternatives to OCS for the management of the challenging patient with SRA and these include high-dose ICS combined with LABA, methlyxanthines, antileukotrienes, and omalizumab. ${ }^{12}$ However, these medications are of variable efficacy and useful only in a limited subset of patients. ${ }^{13}$ In actual fact, a large number of patients with SRA are on frequent, intermittent, or continuous courses of oral prednisolone (in addition to high-dose ICS combined with LABA) with an increased risk of steroid-related adverse events. ${ }^{14}$

Here, we review the practical aspects of patients' management to make sure that patients "labeled" as having SRA truly have SRA, and if so then to discuss the use of add-on therapies both established and novel, including immunological modifiers and biological agents so to propose to physicians a pragmatic management approach in diagnosing and treating this challenging subset of asthmatic patients.

\section{Adherence to medication}

Before developing a roadmap in aid of a pragmatic approach in diagnosing and caring for this troublesome condition, it is important to make sure that the issue of adherence is adequately addressed. Poor asthma control can result from poor adherence to treatment; ${ }^{15,16}$ hence, once the diagnosis of SRA is confirmed then the priority would be exclude compliance to medication as a cause of ongoing symptoms. Detecting poor adherence to medications can be difficult, especially in the busy clinical settings. Ways of checking for adherence may include collection of repeat prescriptions or the measurement of serum prednisolone and cortisol levels in patients on OCS. ${ }^{17}$ It has been reported in a study that $50 \%$ of patients on OCS had low serum levels concentrations of prednisolone and cortisol. ${ }^{18}$ Although, this seems controversial, it signifies that despite having significant symptoms, these patients with SRA are noncompliant with their medication. Hence, better communication between the patient and physician, and patient education is important. ${ }^{19}$ Frequent consultations and patient-centered approaches may be useful ways of improving compliance.

There could be a number of reasons for which the patient may not be adhering to their medications: their perception that the treatment is ineffective, delayed effectiveness of medications (ICS), lack of understanding, poor inhaler technique, antipathy towards asthma and its treatment, monetary reasons, psychosocial causes and attention seeking, stress, and forgetfulness. ${ }^{17}$

\section{Evaluation of severe refractory asthma}

There are no validated algorithms to substantiate the most useful approach to the evaluation of the patient with suspected SRA, but some have been suggested..$^{9,10,17}$ A rational method would involve 3 main aspects:

(a) confirmation of severe asthma

(b) evaluation of other conditions, coexisting conditions and trigger factors

(c) evaluation of the severe asthma subphenotype.

\section{(a) Confirmation of severe asthma}

Many aspects need to be considered prior to prescribing add-on treatments and incremental doses of ICS and OCS to patients thought to have SRA. It is necessary to ascertain whether they genuinely have severe asthma (Figure 1). Hence, first one needs to obtain a detailed history from the patient including details of respiratory symptoms (including chest tightness, wheezing, cough, night and exercise/environmental-related symptoms), the original diagnosis (including who, when, how, and previous investigations), asthma-related morbidity (intensive care/hospital admissions, hospital length of stay, number of exacerbations per year, exacerbating factors, and severity of symptoms), associated comorbidities (including chronic rhinosinusitis disease, cardiac conditions, gastrooesophageal reflux, obesity, and psychological factors), family history, smoking history, and current medication (including compliance, technique, intolerance to medications, and new medications). Second, a thorough physical examination of both respiratory and cardiovascular systems is essential. Third, 


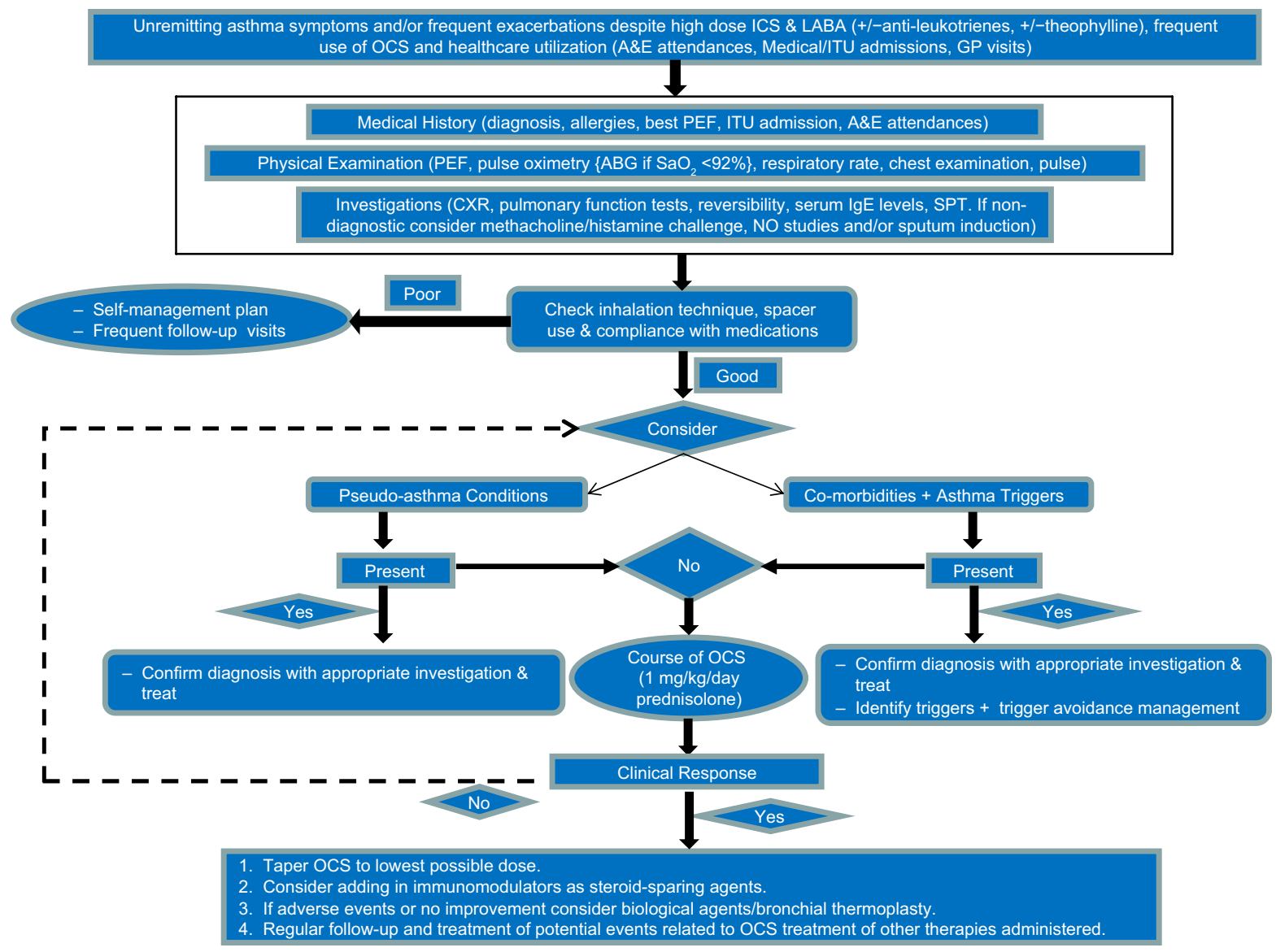

Figure I Algorithm summarizing the strategies and mechanisms of managing subjects with suspected severe refractory asthma (SRA).

Abbreviations: ICS, inhaled corticosteroids; LABA, long-acting beta $2\left(\beta_{2}\right)$-agonists; OCS, oral corticosteroids; A\&E, accident and emergency; ED, emergency department; ITU, intensive therapy unit; GP, general practitioner; PEF, peak expiratory flow; ABG, arterial blood gas; CXR, chest X-ray; IgE, immunoglobulin E; SPT, skin prick testing; NO, nitric oxide.

previous investigations, in particular full blood count, total immunoglobulin E (IgE), autoimmunity, pulmonary function tests, plain chest X-ray, and saturation oximetry (or sometimes arterial blood gases) should be carefully reviewed and if necessary repeated. The pulmonary function tests should include actual and predicted values for forced expiratory volume in 1 second $\left(\mathrm{FEV}_{1}\right)$, forced vital capacity, and small airways (forced expiratory flow $\left[\mathrm{FEF}_{25-75}\right]$ ) to document the presence of airflow limitation. Simultaneous assessment of $\mathrm{FEV}_{1}$ reversibility to $400-800 \mu \mathrm{g}$ inhaled salbutamol ${ }^{20}$ is helpful. In addition, fall in $\mathrm{FEV}_{1}$ when tapering steroid treatment can be also used to document variable airflow limitation and steroid dependency.

Occasionally, reversibility testing may not be conclusive and confirmatory tests including bronchial provocation challenge $\mathrm{s}^{21}$ (using methacholine or mannitol ${ }^{22}$ ), exhaled nitric oxide measurements, and exercise testing may be required. In patients without positive challenge test with bronchial provocation, alternative diagnosis(es) should be considered. Further, more directed investigations to exclude other conditions should be considered to alternative diagnosis(es) be suspected (see later); these may be in addition to or instead of asthma.

\section{(b) Evaluation of other conditions, coexisting conditions and trigger factors} (i) Evaluation of other conditions (pseudoasthma)

Other conditions should be taken in consideration in the differential diagnosis of SRA (Figure 1). A diagnostic work-up of SRA assumes that these conditions should be excluded systematically ${ }^{1,10}$ Taking a detailed history may arouse suspicion of other conditions and appropriate investigations can confirm or exclude these. These conditions and appropriate investigations include the following (Table 1).

\section{Bronchiectasis}

Taking a detailed history of childhood and partially treated respiratory infections as well as a history of cough, breathlessness, and sputum production may direct you to 
Table I Examples of diagnostic tools that can assist in distinguishing severe asthma from alternative conditions that may mimic asthma

\begin{tabular}{l}
\hline Suspected alternative diagnosis \\
Intrabronchial obstruction \\
Vocal cord dysfunction \\
Dysfunctional breathing/panic attacks
\end{tabular}

Recurrent microaspiration

CF

ABPA

Emphysema

Hypersensitivity pneumonitis

Bronchiectasis (including ABPA and CF)

Recurrent pulmonary embolism

Pulmonary arterial hypertension

Bronchiolitis

Sarcoidosis

Churg-Strauss syndrome

Abbreviations: ABPA, allergic bronchopulmonary aspergillosis; CF, cystic fibrosis; lgE, immunoglobulin E; CT, computed tomography; US, ultrasound.

think of bronchiectasis. On examination, patients may most commonly have crackles, rhonchi, wheezing, and inspiratory squeaks on auscultation. Occasionally, they may also present with digital clubbing, cyanosis, plethora, wasting, and weight loss. A high resolution computed tomography (HRCT) scan may help to diagnose this.

\section{Interstitial lung disease}

Not only a history of progressive breathlessness, but also appropriate history of medication and examination should cause suspicion of interstitial lung disease (ILD). On examination, patients may present with digital clubbing, cyanosis, weight loss, wheezing, end inspiratory fine crepitations, desaturation and breathlessness on exertion, as well as signs of the disease causing the ILD. An HRCT would be helpful diagnostically.

\section{Chronic obstructive pulmonary disease}

Diagnostic confusion is common between SRA and chronic obstructive pulmonary disease (COPD), particularly in the middle-aged patient presenting with cough and mild exertional dyspnea who also smokes cigarettes. ${ }^{23}$ Differentiating between SRA and COPD can be achieved by taking careful patient history and by looking at the appropriate investigations, but neither should be used in isolation to differentiate them.

\section{Allergic bronchopulmonary aspergillosis}

Care must be taken to exclude allergic bronchopulmonary aspergillosis (ABPA) by investigating for specific criteria for diagnosis, some of which include elevated total IgE and specific IgE and/or IgG to Aspergillus fumigatus, positive skin prick test to A fumigatus, and central bronchiectasis on HRCT. ${ }^{24}$ Delay in diagnosis and treatment may lead to permanent damage to the lungs.

\section{Churg-Strauss vasculitis}

The early stage of Churg-Strauss syndrome exhibits substantial overlap with severe asthma, which makes diagnosis difficult. However, unlike severe asthma, Churg-Strauss syndrome may progress into a life-threatening systemic vasculitis, with vascular and extravascular granulomatosis. A diagnosis of Churg-Strauss vasculitis may difficult to tease out as often it manifests a number of overlapping symptoms involving several organ systems. ${ }^{25}$ Laboratory abnormalities include anemia, persistent eosinophilia, raised erythrocyte sedimentation rate, and positive antineutrophil cytoplasmic antibody (in about $30 \%-50 \%$ of cases). Diagnostic confirmation can be obtained by biopsy of the lung or other clinically affected tissues. Like ABPA, prompt diagnosis and treatment are important to avoid irreversible sequel to the lungs. Treatment often includes highdose OCS and cytotoxic/immunosuppressive therapy.

\section{Vocal cord dysfunction}

Vocal cord dysfunction may mimic SRA, presenting with wheezing, cough and breathlessness that is episodic, beginning and remitting abruptly, and nonresponsive to asthma treatments. ${ }^{26}$ Of note, in these patients expiratory loop and flows are preserved, but inspiratory loop is flattened reflecting reduced flow due to vocal cords partially opposing during inspiration, causing partial flow obstruction. Diagnosis is made by direct visualization of the vocal cords by laryngoscopy when the patient is symptomatic. ${ }^{27}$

\section{Cardiac disease}

Occasionally, congestive heart failure may present with a cardiac wheeze and masquerade SRA. ${ }^{28}$ On examination, patients may present with tachypnea, crackles on auscultation (normally at the bases), displaced apex beat, elevated jugular venous pressure, and peripheral edema depending on the type of heart failure. Occasionally, they may also present with cyanosis, gallop rhythm, pleural effusions, murmurs, etc. Electrocardiograms, cardiopulmonary exercise testing, echocardiography, and/or cardiac angiography may be helpful to identify any cardiac causes. If a cardiac cause is proved, 
treatment would obviously be directed towards this and not increase antiasthma medications.

\section{(ii) Evaluation of coexisting conditions and trigger factors}

It has been reported that other conditions can coexist alongside severe asthma, and these may present, if untreated, with asthma-like symptoms. ${ }^{18,28}$ Hence, coexisting conditions need to be carefully identified and managed, as it may improve the patients' symptoms and prevent further escalation of asthma medications (Figure 1). Remember, taking a detailed history may arouse suspicion other comorbidities or appropriate investigations confirm these. Some of these conditions and appropriate investigations are as follows.

\section{Chronic rhinosinusitis}

Chronic rhinosinusitis is frequently associated with SRA S2,30 $^{29,}$ and nasal polyposis is often related to aspirin (and/or nonsteroidal anti-inflammatory drugs [NSAIDs]) intolerance and a more severe asthma phenotype. ${ }^{31-33}$ Symptoms of rhinosinusitis include nasal congestion and obstruction, purulent nasal discharge, maxillary tooth discomfort, and facial pain or pressure. Other signs and symptoms include fever, fatigue, cough, hyposmia or anosmia, ear pressure or fullness, headache, and halitosis. Diagnosis is confirmed by nasal endoscopy and computed tomography-imaging of the sinuses. Medical (nasal and/ or systemic corticosteroids, immunotherapy, antihistamines, and antibiotics) or surgical treatment of upper airway disease can improve asthma control. Therefore, patients with severe asthma should be systematically evaluated and treated for rhinosinusitis with or without nasal polyps (Table 2).

\section{Gastroesophageal reflux disease}

Gastroesophageal reflux disease (GERD) is common among patients with asthma, but often causes mild or no symptoms.
Although it has been suggested as a pathophysiological link between gastroesophageal reflux and asthma, the exact relationship between the 2 conditions has not been fully established. ${ }^{34}$ GERD may be suspected in patients with heartburn, regurgitation, and dysphagia. Less common symptoms include odynophagia, excessive salivation, nausea, chest pain, chronic cough, laryngitis, erosion of dental enamel, and hypersensitivity. Although detection of GERD is ideally obtained by 24-hour $\mathrm{pH}$ monitoring, many physicians prefer to give an empiric therapy trial of $\geq 3$ months with high-dose proton pump inhibitors (PPI; Table 2). PPIs have shown to reduce asthma symptoms in some studies, ${ }^{35,36}$ but not in others. ${ }^{37,38}$ Treatment with PPI does not improve asthma control and is unlikely to be the cause of the poorly controlled asthma. ${ }^{38}$ No specific studies have been carried out in the subset of patients with SRA.

\section{Psychosocial factors}

Subjects with asthma are more likely to be treated for a mental health problem (depression, anxiety, and panic disorders) and demonstrate more negative social outcomes. ${ }^{39}$ This is more so if the patient has severe disease or has had a life-threatening episode. ${ }^{17,40}$ In addition, anxiety disorders ${ }^{41}$ and acutely negative affective disorders ${ }^{42}$ have also been shown to have an impact on asthma. In an open-labeled study of 75 patients with SRA, it was reported that 33 had a psychiatric element to their asthma and in 10 of those this was thought to be "major." 18 Specialist help from a psychiatrist is needed to establish the correct diagnosis and its significance. However, it is still controversial as to whether treatment of the psychological condition may lead to an overall improvement in asthma control and severity.

\section{Drugs}

Various drugs can provoke an asthma attack or worsening asthma symptoms. Some of these include $\beta$-blockers, aspirin, NSAIDs, ${ }^{18}$ angiotensin converting enzyme inhibitors,

Table 2 Diagnostic tools and treatment of most common comorbidities in severe asthma

\begin{tabular}{lll}
\hline Comorbid condition & Diagnostic test & Treatment \\
\hline Gastroesophageal reflux & $\begin{array}{l}\text { 3 months empiric therapy trial with } \\
\text { high dose PPI or esophageal pH testing }\end{array}$ & Lifestyle modifications \\
& & PPIs \\
Obesity with or without & BMI \pm polysomnography & Weight control \\
obstructive sleep apnea syndrome & & Positive airway pressure \\
& & Oral appliances \\
Sinus disease & CT-scan Rhinoscopy (for sinus discharge) & Surgery \\
& & Nasal irrigation with saline \\
& & corticosteroid spray \\
& & corticosteroid drops \\
\end{tabular}

Abbreviations: PPI, proton pump inhibitors; BMI, body mass index; CT, computed tomography. 
and estrogens. Likewise, food intolerances can have similar effects on asthma control.

\section{Smoking}

Cigarette smoking has multiple negative effects on asthma. Accelerated decline in lung function over time is present in asthmatic individuals who smoke. ${ }^{43}$ Smokers with asthma are more symptomatic and have more severe and frequent exacerbations and emergency care needs. ${ }^{44}$ Asthma mortality is greater among asthmatics who smoke cigarettes compared with asthmatics who do not smoke. ${ }^{45}$ In addition, asthmatic patients who smoke appear to have a reduced therapeutic response to both inhaled and OCSs. ${ }^{46,47}$ Last but not least, recent research has shown that cigarette smoking is an important independent risk factor for new onset asthma in allergic individuals. ${ }^{48}$ Hence, smoking cessation is also critical in the management of the patient with SRA who smokes.

\section{Allergens and trigger factors}

Unusual asthma triggers is a vital component that requires addressing and may be helpful in managing the patient. Triggers could be exogenous or endogenous, the latter of which can be related to the comorbidities discussed early, such as respiratory infections, gastroesophageal reflux, psychological triggers, etc. Exogenous factors include allergens ${ }^{49}$ or occupational/domestic sensitizers that may boost the inflammatory response of the underlying asthma and enhance BHR, thus contributing to the severe asthma phenotype. ${ }^{1}$ A recent study has reported that specific work environments are associated with the development of severe asthma. ${ }^{50}$ Dissecting out the individual role of exogenous or endogenous factors requires a high level of suspicion and great skills in history taking.

\section{Obesity}

The European Network for Understanding Mechanisms of Severe Asthma study has reported that patients with more severe disease are women with a component of irreversible airflow obstruction, neutrophilic inflammation, reduced atopy, and with a larger body mass index. ${ }^{2}$ There is also accumulating evidence that obese patients have an increased risk of developing asthma. ${ }^{51}$ Although asthma and obesity are frequently associated, the contribution of obesity to severe asthma as well as the mechanisms responsible for this relationship are not fully clarified. Although morbid obesity is positively associated with reduced lung volumes and the presence of comorbid aggravating factors, including gastric reflux, obstructive sleep apnea syndrome, and psychological factors, ${ }^{52}$ the overall strength of the relationship between obesity and severe asthma appears to be modest $^{53}$ (Table 2). Although the evidence that weight control interventions are associated with improvements in asthma control remains controversial, ${ }^{54,55}$ weight reduction should be strongly encouraged anyhow.

\section{(c) Evaluation of severe asthma subphenotype}

By systematically addressing conditions and factors according to the diagnostic work-up illustrated earlier, it is possible to define patients with truly SRA. However, this subgroup is far from being homogeneous and may be further subdivided into different phenotypes. Phenotyping of patients with SRA is becoming increasingly important because it may help to guide current and possibly future treatments. However, the true significance of phenotyping SRA can be firmly established only when detailed characterization of hundreds of patients will be completed and analyzed, as proposed in the newly established pan-European consortium Unbiased Biomarkers for the Prediction of Respiratory Disease Outcome funded by the Innovative Medicines Initiative in its program Understanding Severe Asthma. ${ }^{56}$

In clinical practice, most patients with severe asthma are by and large belonging to 3 categories: (1) those suffering from frequent severe exacerbations with relatively stable episodes between exacerbations (exacerbation prone asthma), (2) those who develop irreversible airflow obstruction (asthma with fixed airflow obstruction), and (3) those who depend on systemic corticosteroids for daily control of their asthma (steroid-dependent asthma). ${ }^{10}$

From a pathological point of view at least 2 phenotypes of severe asthma have been proposed, each associated with distinct clinical and pathophysiological characteristics. These subtypes include the persistent eosinophilic and noneosinophilic forms of severe asthma. ${ }^{57}$

\section{Management of severe refractory asthma}

Treatment of SRA remains highly problematic and regular systemic corticosteroids are often needed to minimize symptoms. Hence, SRA patients not only are at risk of dying from their asthma, but also from the comorbidities associated with the excessive steroid use., ${ }^{7,58}$ Patients with such severe disease that is unremitting to guideline-based management may be better looked after at dedicated clinics where patients would be assessed for alternative diagnoses and comorbidities, adequately phenotyped using more specialized investigative methods, and optimally managed with the best 
possible treatments available, and where patients may also have facilitated access to a multidisciplinary team (physicians, ear, nose, and throat specialists, psychologists, pharmacists, and specialist nurses). ${ }^{17}$ However, only a few tertiary asthma centers are available..$^{59}$

Optimal treatment of SRA should be aimed at achieving the best possible asthma control and quality of life (Qol) with the least dose of medication (particularly systemic corticosteroids). The choice and formulation of therapeutic agents to be used should be dictated by disease severity, therapeutic response, patient's comorbidities and preferences, as well as on the agents' adverse event profile. These include:
(a) standard therapies
(b) immunomodulatory agents
(c) biological and other novel therapies.

\section{Standard therapies}

Standard treatment for patients with severe asthma includes high-dose ICS ( $\geq 1,200 \mu \mathrm{g} /$ day or equivalent of beclomethasone) in combination with a LABA. There are a number of combined inhalers in the market that can also used with a spacer device. ${ }^{6}$ Therefore, if a patient has not been on high-dose ICS (along with LABA), a trial is certainly warranted. ${ }^{60}$ More recently, there have been suggestions that an ICS with smaller particle size for more distal penetration of the airways to improve inflammation in smaller airways has been proposed, but its efficacy has yet to be evaluated in SRA. ${ }^{9}$ Although it has been reported that the use of LABA may reduce the dose of ICS by $57 \%,{ }^{61}$ they may not be as efficacious in patients with SRA than in moderate persistent asthma. ${ }^{62,63}$ Leukotriene antagonists may be beneficial in some patients with severe asthma, especially those with aspirin sensitivity. ${ }^{2,64}$ Other drugs used in which reports of improvements in patients with SRA, but not assessed by randomized clinical trials, include anticholinergics, ${ }^{65,66}$ theophyllines, ${ }^{67,68}$ and intravenous (IV) magnesium. ${ }^{69,70}$ Hence, a trial of these agents may prove useful.

Inspite of using these additional therapies, there is a subgroup of patients with severe unremitting disease who require high doses of OCS ( $\geq 30 \mathrm{mg}$ /day) on a daily basis to attain an adequate level of control of their symptoms and QoL. This subgroup of patients often exhibits deterioration of their asthma symptoms as soon as the dose of corticosteroids is tapered. Hence, reasonable control of their asthma can only be achieved at the cost of significant morbidity (eg, osteoporosis, diabetes, hypertension, cataract formation, gastrointestinal (GI) bleeding, myopathy, adrenal insufficiency, susceptibility to infections, weight gain, and skin thinning). ${ }^{71,72}$

\section{Immunomodulatory drugs}

To curtail the necessity of prolonged OCS use and the adverse effects associated, a trial with immunomodulatory drugs may be an option. Some of the agents that can be considered include methotrexate, cyclosporine $\mathrm{A}$, and macrolide antibacterials. ${ }^{13}$ Other agents have been investigated but are not commonly used and include azathioprine, gold, and IV IGs. ${ }^{13}$ We shall discuss the former 3 agents as they have been more commonly tried as corticosteroid-sparing agents in severe asthma (see Table 3 for summary).

\section{Methotrexate}

Methotrexate is a folic acid inhibitor, but at low doses has immunosuppressive and anti-inflammatory properties. ${ }^{73}$ Methotrexate is the most clinically investigated immunological agents in severe asthma. In total, there have been 11 well-conducted clinical trials published in the literature to evaluate the efficacy and safety of methotrexate in SRA. ${ }^{13}$ The trials involved the use of methotrexate administered orally at dose of 7.5-30 mg on a weekly basis for a period between 12 and 24 weeks in patients who were mostly taking $>10 \mathrm{mg}$ of prednisolone daily. Some of them had run-in periods and were

Table 3 Summary of evidence of efficacy of the immunomodulatory, biological, and other therapies in severe refractory asthma

\begin{tabular}{|c|c|c|}
\hline Agent & $\begin{array}{l}\text { Evidence for efficacy } \\
\text { (Reference in text) }\end{array}$ & Study type \\
\hline \multirow[t]{4}{*}{ Methotrexate } & Trigg et $\mathrm{a}^{76}$ & PCC \\
\hline & Hedman et al ${ }^{75}$ & PCC \\
\hline & Comet et $\mathrm{al}^{74}$ & DBPC \\
\hline & Domingo et a ${ }^{79}$ & OS \\
\hline \multirow[t]{3}{*}{ Cyclosporine A } & Lock et a ${ }^{87}$ & DBPC \\
\hline & Nizankowska et al ${ }^{88}$ & DBPC \\
\hline & Alexander et a ${ }^{89}$ & PCC \\
\hline Macrolides & Ball et al ${ }^{99}$ & DBPC \\
\hline \multirow[t]{2}{*}{ Troleadomycin } & Kamada et al ${ }^{100}$ & DBPC \\
\hline & Nelson et $\mathrm{al}^{101}$ & DBPC \\
\hline \multirow[t]{3}{*}{ Clarithromycin } & Garey et al ${ }^{102}$ & CS \\
\hline & Gotfried et al ${ }^{103}$ & DBPC \\
\hline & Simpson et al ${ }^{104}$ & DBPC \\
\hline Omalizumab & Walker et al'"I & $\mathrm{CR}$ \\
\hline Anti-TNF- $\alpha$ therapy & Berry et al ${ }^{123}$ & PCC \\
\hline \multirow[t]{2}{*}{ Etanercept } & Howarth et al ${ }^{124}$ & OS \\
\hline & Morjaria et al ${ }^{125}$ & DBPC \\
\hline Golimumab & Wenzel et al ${ }^{126}$ & DBPC \\
\hline Mepolizumab (anti-IL5) & Haldar et $\mathrm{al}^{134}$ & DBPC \\
\hline Daclizumab (anti-CD25) & Busse et $\mathrm{al}^{140}$ & DBPC \\
\hline \multirow[t]{4}{*}{ Bronchial thermoplasty } & Cox et al ${ }^{145}$ & OS \\
\hline & Cox et al $\left.\right|^{146}$ & DBPC \\
\hline & Pavord et al ${ }^{147}$ & DBPC \\
\hline & Castro et al $^{148}$ & DBPC \\
\hline
\end{tabular}

Abbreviations: PCC, placebo-controlled crossover study; DBPC, double-blind placebo-controlled study; OS, observational study; CS, case series; CR, cochrane review; TNF, tumor necrosis factor; IL, interleukin. 
either placebo-controlled crossover (PCC) or double-blind placebo-controlled studies (DBPC). Only one of the studies had patients on methotrexate for a period of 12 months. ${ }^{74} \mathrm{Of}$ all the studies, the 3 larger ones showed that the administration of methotrexate had a significant reduction in the OCS dose. ${ }^{74-76}$ None-life-threatening adverse events that were transient and reversible on stopping methotrexate administration including abnormal liver function tests, GI symptoms, oral ulcers, and stomatitis were noted. Of note, in 2 separate prospective open-labeled extension studies for up to 28 weeks, oral methotrexate at $15 \mathrm{mg}$ weekly were reported to result in a significant OCS dose reduction, and in fact more than half of the patients came off their OCS completely. ${ }^{77,78}$ In addition, in a large case series of patient with SRA treated with low dose methotrexate for up to 12 years it has been shown a substantial, safe decrease in OCS (OCSs were withdrawn completely in $59 \%$ of patients). ${ }^{79}$ Taken together, these findings show that prolonged administration of methotrexate will be necessary to achieve significant OCS reduction or to wean off OCS completely.

Three meta-analyses have been published in the literature on methotrexate in SRA of the a number of the 11 studies conducted showing a small but significant OCS dose reduction with use of methotrexate. ${ }^{80-82}$ Also, no other subjective or objective parameters have been noted to be significantly altered with the administration of methotrexate. Although there were no predicting factors in the "responders," these studies have shown that there are some subgroups of SRA patients who have benefited from the use of oral methotrexate. Hence, as in the treatment of rheumatological and dermatological conditions, the risk-benefit profile of methotrexate is preferable to that of the long-term use of OCS at doses $>10 \mathrm{mg} /$ day; thus, we recommend that methotrexate should be the first choice of steroid-sparing immunomodulator therapy for patients with SRA.

\section{Cyclosporine A}

Cyclosporine A works by inhibiting the activation of T cells. $\mathrm{T}$ cells have been implicated in the pathogenesis of asthma and hence the drive to investigate its efficacy in asthma. ${ }^{83-86}$ To date, there have been 3 published studies of the use of cyclosporine A at a dose of $5 \mathrm{mg} / \mathrm{kg} /$ day in SRA patients on a mean dose of $>8.5 \mathrm{mg} /$ day of prednisolone in the literature (2 $\mathrm{DBPC}^{87,88}$ and $1 \mathrm{PCC}^{89}$ ) for a period of 12-36 weeks. Among the 3 studies conducted, there were significant improvements in lung function, symptom scores, and reliever use; however, all 3 studies reported a significant reduction in OCS dose in the patients. Although in the conducted studies only minor adverse events of mild renal impairment, worsening of preexisting hypertension, paraesthesia, tremor, headaches, flu-like illness, and increased hypertrichosis were noted, these reversed on stopping the cyclosporine A. ${ }^{87-91}$ Notably, there is always the dose-dependent nephrotoxicity concern based on the experience of transplant literature.

A meta-analysis of 3 studies using cyclosporine A in SRA has reported that the use of cyclosporine $\mathrm{A}$ is associated with a minor reduction in the OCS dose in these patients, ${ }^{92}$ but this is on the background of safety concerns of worsening hypertension and renal function. Furthermore, although we do not have any long-term studies in SRA, long-term use in other chronic inflammatory conditions such as rheumatoid arthritis (RA) and ulcerative colitis (UC) are burdened by substantial failure rates. ${ }^{93,94}$ Hence, not only do patients require close monitoring but also the risk of failure with cyclosporine A. With this in mind, future studies should be conducted with the use of newer cyclosporine A analogs, tacrolimus, and pimecrolimus, which have better safety profiles and more efficacious in corticosteroid-resistant conditions.

\section{Macrolide antibacterials}

Originally, macrolides (eg, troleadomycin) have been used in SRA, not for their antibacterial properties but for their steroid-sparing effects. ${ }^{95,96}$ Important benefits have also been noted with newer macrolides based on their anti-inflammatory effects..$^{97,98}$ Three DBPC studies ${ }^{99-101}$ have looked into the safety and efficacy of troleadomycin in patients with OCSdependent asthma, of which 2 were small and conducted in children. ${ }^{99,100}$ These latter 2 small studies reported substantial OCS dose reduction use and airway hyperresponsiveness (AHR). ${ }^{99,100}$ In the larger study that spanned 12 months, 75 SRA patients on OCS were recruited and reported in those that completed the study that there was a significant reduction in OCS daily use; however, this was not associated with a reduction in the number of emergency department (ED) attendance and admissions, asthma control, and AHR. ${ }^{101}$ Newer macrolides have been used demonstrating not only similar reductions in daily OCS use or weaning off OCS completely, but also airway inflammation and subjective parameters. ${ }^{102-104}$ Troleadomycin, with its steroid metabolism activity on the cytochrome P450 complex was associated with not only increased the steroid-related adverse events, but also direct events such as GI symptoms and hepatotoxicity ranging from transient liver enzyme abnormalities to cholestatic jaundice; hence, its use has been discontinued. However, the use of clarithromycin has not been associated with any major adverse events in the published literature. 
Although initial data on the use of clarithromycin show that there is some benefit in the use of macrolides in SRA, more robust, well-conducted DBPC studies are needed to evaluate their true value.

\section{Biologics and other therapies}

Due to the refractoriness to OCS and/or immunomodulators, or adverse events to the latter novel strategies have been developed to evaluate alternative therapies in these SRA patients. These may be useful in a steroid-sparing or steroid-replacement role. These include the licensed omalizumab, and other drugs that have not been so efficacious or safe, and others with only small DBPC trial data (see Table 3 for summary).

\section{Omalizumab}

IgE has central pathophysiological role in the development of allergic conditions by enhancing dendritic cell allergen uptake, and activation and release of inflammatory mediators by mast cells and basophils. ${ }^{105,106}$ Omalizumab is a humanized IgE-specific monoclonal antibody that prevents interaction of IgE to FceR1 receptors on effector cells. ${ }^{107,108}$ Early pharmacodynamic studies have reported that omalizumab reduces inflammation, AHR, and allergen-induced airway and skin tests. ${ }^{109,110}$

There have been 6 large DBPC studies, evaluating over 2,500 patients, that have been conducted to assess the safety and efficacy of omalizumab in severe atopic asthmatics who had persisting symptoms despite optimum treatment. ${ }^{111}$ Omalizumab is administered either 2-weekly or 4-weekly depending on the weight and IgE levels, in patients with an IgE level between 30-700 IU/ml over 25-52 weeks in the various studies. Pooled analyses of the studies have reported that the addition of omalizumab has beneficial improvements in the reduction of exacerbations, reduction in ED attendances, asthma-related QoL, asthma symptoms, lung function as well as reduction in steroid reliever usage. ${ }^{11-115}$ Also reported was that the therapeutic response of omalizumab is best assessed at 16 weeks after initiation to justify its continuation. In addition, compared with placebo, patients treated with omalizumab did not have significantly more adverse events. Most of the adverse events were minor such as headaches, cough, GI symptoms, urticaria, and injection-site reactions. ${ }^{116}$ There have been postmarketing reviews suggesting that there are slightly increased number of anaphylactic and anaphylactoid reactions, malignant neoplasms, and helminth infections in patients treated with omalizumab and that caution and vigilance of these need to be in the clinicians mind. ${ }^{105,116,117}$
The number of patients with severe atopic asthma is small and it is only in around two-thirds of these that omalizumab may be effective and hence the 16-week and regular assessment of its efficacy and safety need to be in reviewed, but also that the large majority of SRA patients are nonatopic and hence the use of omalizumab may be a limited option. Besides, the use of omalizumab is not licensed in severely atopic patients and its cost is a limiting feature. In England, the National Institute of Clinical Excellence advises the use of omalizumab in patients who have had 2 or more ED attendances and/or hospital admission due to lack of control of their asthma despite optimal therapy. ${ }^{105}$ Other criteria include atopy to at least a common allergen, and compliance and adherence to asthma medications.

\section{Anti-tumor necrosis factor alpha drugs}

Anti-tumor necrosis factor alpha (TNF- $\alpha$ ) is a multifunctional proinflammatory $\mathrm{TH} 1$ cytokine. Corticosteroids fail to reduce TNF- $\alpha$ and TH1 cytokines in asthmatic airways and hence explain the lack of steroid efficacy in these severe asthma patients. ${ }^{118}$ TNF- $\alpha$ has been implicated in the various pathological processes of asthma. ${ }^{119}$ Hence, the trial of anti-TNF- $\alpha$ agents in SRA was considered. Importantly, anti-TNF- $\alpha$ agents are widely used in other TH1-mediated chronic conditions such as RA, psoriasis, Crohn disease, and ankylosing spondylitis with good efficacy and safety. ${ }^{120}$

In mild and moderate asthma, anti-TNF- $\alpha$ treatment has proved to be noneffective. ${ }^{121,122}$ Two initial small studies of anti-TNF- $\alpha$ treatment, using the soluble receptor etanercept, showed that there were marked improvements in subjective (asthma-related control and QoL) as well as objective (spirometry, peak flows, and AHR) measures of asthma and reduction in reliever medication use. ${ }^{123,124}$ More recent larger studies using etanercept ${ }^{125}$ and the monoclonal antibody, golimumab, ${ }^{126}$ have shown that there were minimal or no important changes in asthma measures. In fact, in the latter study the trial was terminated early due to the increased number of patients who developed solid malignancies and serious infections. Safety of anti-TNF- $\alpha$ agents comes mainly from studies of rheumatological conditions, including increased risk of malignancies, opportunistic infections and reactivation of tuberculosis, demyelination, and cardiac failure. ${ }^{19,127}$ In the asthma studies besides the major adverse events noted in the golimumab study, only minor adverse events were noted including injection-site reactions, rashes, respiratory tract and asthma exacerbations, and headaches. ${ }^{122-125}$

The role of anti-TNF- $\alpha$ agents in severe asthma, although initially looked promising, were darkened by the outcomes of 
the larger studies both in terms of efficacy and safety. Of note, there are floors in the larger studies including recruiting of milder patients, short treatment, and observation periods. It also seems that the soluble receptor, etanercept, is associated with less severe adverse event and more efficacy.

However, in view the findings of anti-TNF- $\alpha$ agents are no longer under trial or use in severe asthma.

\section{Mepolizumab (anti-IL-5)}

Th2 cytokines, namely interleukin (IL)-4, 4, 5, 9, 13 and granulocyte-macrophage colony-stimulating factor, are expressed in elevated amounts in severe disease. ${ }^{128}$ Monoclonal IL-5 antagonists have been studied in varying severities of asthma, but have not shown any symptom or physiological improvements. ${ }^{129-132}$ However, they have shown significant reductions in circulating, bone marrow and airway eosinophilia, trend towards reduced risk of moderate/severe exacerbations and attenuation of airway remodeling. ${ }^{131,133}$

In a recent study, Haldar et $\mathrm{al}^{134}$ studied the efficacy of anti-IL-5 therapy using mepolizumab in patients with eosinophilic refractory asthma in DBPC fashion for 12 months. They reported a significant reduction in severe asthma exacerbations (primary outcome) and associated reductions in blood and sputum eosinophilia. Akin to previous studies, there were no significant changes in subjective or objective markers of asthma, but there was a small significant reduction in percentage (not actual) steroid usage in the mepolizumab group compared with placebo. The beneficial effects of mepolizumab have also been shown in another prednisolone withdrawal study in severe eosinophilic asthma. ${ }^{135}$ The use of mepolizumab was not associated with any significant major or minor adverse events compared with placebo.

These 2 studies show that in a small subgroup of patients with asthma who continue to have sputum eosinophilia even after treatment with OCS and high-dose ICS, treatment with mepolizumab may be effective in reducing asthma exacerbations, steroid use, and potential airway remodeling; however, this needs to be confirmed in larger studies in patients within this specific subgroup.

\section{Daclizumab (anti-CD25)}

It is well known that airway inflammation in asthma involves T-cell activation. It has been reported that there are increased number of activated CD25+ $\mathrm{T}$ cells and increased levels of IL-2 and soluble (s) IL-2 receptor alpha chain ( $\mathrm{sCD} 25$ ) found in the airways of patients with severe asthma. ${ }^{136-139}$ Following T-cell activation, cytokine generation and secretion may contribute to the initiation and potentiation of inflammation along with the development of repair leading to airway remodeling. ${ }^{138}$ Daclizumab is a humanized monoclonal antibody to alpha (CD25) subunit of the high-affinity IL-2 receptor, inhibiting IL-2 binding and thus IL-2's biological activity.

In a DBPC study to evaluate the efficacy and safety of daclizumab in moderate to severe patients with asthma, it was reported that there were small, but significant improvements in $\mathrm{FEV}_{1}$, daytime asthma symptoms, and prolonging of time to exacerbation in the patients on daclizumab compared with controls. ${ }^{140}$ Also, there was marked reduction in reliever use in favor of patients on daclizumab. Although there were no differences in mild and moderate adverse events between the 2 study groups (upper respiratory tract infection, nasopharyngitis, nasal congestion, rash, and nausea), there were more patients with serious adverse events in the daclizumab group including anaphylactoid reaction, viral meningitis, exacerbation of UC, and diabetics.

This small study demonstrates that daclizumab may have a role in asthma and further studies are needed to define its role as an add-on therapy.

\section{Bronchial thermoplasty}

An increase in airway smooth muscle (ASM) is thought to be an important factor in severe and fatal asthma. ${ }^{141,142}$ Bronchial thermoplasty (BT) is the delivery of controlled thermal energy to the airway wall during several bronchoscopy procedures. The application of BT to the airways is an innovative treatment approach to reduce the bronchoconstrictor response in asthma. Preclinical studies have demonstrated that BT results in reduction of the ASM, ${ }^{143,144}$ and animal models have been associated with a long-lasting reduction in AHR. ${ }^{143}$

In a proof-of-concept study in 16 patients with mildto-moderate asthma, it was confirmed that BT results in an improvement in symptom-free days and peak expiratory flow (PEF) at 3 months, and an improvement in AHR with an associated reduction in asthma symptoms and no adverse events for a period of 2 years. ${ }^{145}$ In the Asthma Intervention Research (AIR) trial, which was to assess the efficacy of BT in patients with moderate to severe asthma, it was observed that following BT patients had significantly reduced mild exacerbations and use of reliever medication, improvement in morning PEF, asthma-related QoL, and control compared with controls. ${ }^{146}$ Post hoc analysis suggested that the benefits were greatest in patients with more severe disease. Hence, in a smaller study (Research in Severe Asthma [RISA]) similarly designed to the AIR study, BT was administered in patients with severe asthma and showed similar improvements in outcomes to the 
AIR study. ${ }^{147}$ In both studies (AIR and RISA), there were notable adverse effects of BT and lack of effect on AHR. The significant increased respiratory adverse effects included wheezing, cough, chest discomfort, dyspnoea, productive cough, and discolored sputum in the BT group compared with control. Although both these studies showed improvement in asthma outcomes, there was prudence of the high placebo effect. Thus another study, AIR2, was conducted in severe asthma patients in whom a sham procedure was conducted to overcome the placebo effect. ${ }^{148}$ At 6-12 months post-treatment, BT had a small, but significantly improved asthma-related QoL score compared with sham control. Of note, there are no differences between the 2 treatments in any of the secondary outcome measures, but safety assessments showed less (but nonsignificant) severe exacerbations and ED attendances in the BT group compared with the sham control group.

Overall, the AIR2 study has demonstrated disappointing outcomes for BT. Severe asthma has many phenotypes, and in which phenotype BT may be efficacious requires further work. Also, the risk-benefit ratio of BT in these patients with steroids refractory disease needs to be assessed.

\section{Conclusion and the future}

Managing asthma that is refractory to standard treatment requires a systematic approach to evaluate adherence, ensure a correct diagnosis, and identify coexisting disorders and trigger factors. In future, phenotyping of patients with SRA will also become an important element of this systematic approach, because it could be of help in guiding and tailoring treatments.

Treatment of SRA remains highly problematic and regular systemic corticosteroids are often needed to minimize symptoms. Despite the unquestionable beneficial role of systemic corticosteroids for most patients with SRA, they do not seem to be effective in every patient and they are associated with severe adverse side effects. Moreover, immunomodulatory and biologic therapies reportedly lack high levels of efficacy, show wide variation in success rates across studies, and are associated with adverse side effects.

Consequently, there is a compelling need for more effective drugs for these challenging patients. Identifying medications that reduce the need for systemic corticosteroids in patients with SRA should be a priority for the academic world and the pharmaceutical industry.

\section{Disclosure}

Riccardo Polosa has participated as a speaker for CV Therapeutics, Novartis, Merck and Roche. He is also a consultant for CV Therapeutics, Duska Therapeutics and NeuroSearch.

\section{References}

1. Holgate ST, Polosa R. The mechanisms, diagnosis, and management of severe asthma in adults. Lancet. 2006;368(9537):780-793.

2. The ENFUMOSA cross-sectional European multicentre study of the clinical phenotype of chronic severe asthma. European network for understanding mechanisms of severe asthma. Eur Respir J. 2003;22(3): $470-477$.

3. Van Ganse E, Laforest L, Pietri G, et al. Persistent asthma: disease control, resource utilisation and direct costs. Eur Respir J. 2002;20(2):260-267.

4. Antoncelli L, Bucca C, Neri M, De Benedetto F, Saabbatani PBF Asthma severity and medical resource utilization. Eur Respir J. 2004; 23:723-729.

5. Godard P, Chanez P, Siraudin L, Nicoloyannis N, Duru G. Costs of asthma are correlated with severity: a 1-yr prospective study. Eur Respir J. 2002;19(1):61-67.

6. Global Initiative for Asthma. Global strategy for asthma management and prevention. A six part management program. NIH publication number 02-3659. 2006.

7. Chung KF, Godard P, Adelroth E, et al. Difficult/therapy-resistant asthma: the need for an integrated approach to define clinical phenotypes, evaluate risk factors, understand pathophysiology and find novel therapies. ERS Task Force on Difficult/Therapy-Resistant Asthma. European Respiratory Society. Eur Respir J. 1999;13(5):1198-1208.

8. Wenzel S, Fahy JV, Irvin CG, Peters SP, Spector S, Szefler SJ. Proceedings of the ATS Workshop on Refractory Asthma: current understanding, recommendations and unanswered questions. Am J Respir Crit Care Med. 2000;162:2341-2351.

9. Wenzel S. Severe asthma in adults. Am J Respir Crit Care Med. 2005; 172(2):149-160.

10. Polosa R, Benfatto GT. Managing patients with chronic severe asthma: rise to the challenge. Eur J Intern Med. 2009;20(2):114-124.

11. Chanez P, Wenzel SE, Anderson GP, et al. Severe asthma in adults: what are the important questions? JAllergy Clin Immunol. 2007;119(6): 1337-1348.

12. GINA Report, Global Strategy for Asthma Management and Prevention. NIH publication number 02-3659. 2009

13. Polosa R, Morjaria J. Immunomodulatory and biologic therapies for severe refractory asthma. Respir Med. 2008;102(11):1499-1510.

14. Bucknall CE, Slack R, Godley CC, Mackay TW, Wright SC. Scottish Confidential Inquiry into Asthma Deaths (SCIAD), 1994-6. Thorax. 1999;54(11):978-984.

15. Bender BG. Overcoming barriers to nonadherence in asthma treatment. J Allergy Clin Immunol. 2002;109 Suppl 6:S554-S559.

16. Weinstein AG. Should patients with persistent severe asthma be monitored for medication adherence? Ann Allergy Asthma Immunol. 2005; 94(2):251-257.

17. Currie GP, Douglas JG, Heaney LG. Difficult to treat asthma in adults BMJ. 2009;338:b494.

18. Robinson DS, Campbell DA, Durham SR, Pfeffer J, Barnes PJ, Chung KF. Systematic assessment of difficult-to-treat asthma. Eur Respir J. 2003;22(3):478-483.

19. Cochrane GM, Horne R, Chanez P. Compliance in asthma. Respir Med. 1999;93(11):763-769.

20. Moore WC, Bleecker ER, Curran-Everett D, et al. Characterization of the severe asthma phenotype by the National Heart, Lung, and Blood Institute's Severe Asthma Research Program. J Allergy Clin Immunol. 2007;119(2):405-413.

21. British Thoracic Society and Scottish Intercollegiate Guideline Network. British guideline on the management of asthma. Thorax. 2008; 63 Suppl 4:iv1-iv121.

22. Crapo RO, Casaburi R, Coates AL, et al. Guidelines for methacholine and exercise challenge testing-1999. This official statement of the American Thoracic Society was adopted by the ATS Board of Directors, July 1999. Am J Respir Crit Care Med. 2000;161(1):309-329.

23. Tinkelman DG, Price DB, Nordyke RJ, Halbert RJ. Misdiagnosis of COPD and asthma in primary care patients 40 years of age and over. J Asthma. 2006;43(1):75-80. 
24. Greenberger PA. Allergic bronchopulmonary aspergillosis, allergic fungal sinusitis, and hypersensitivity pneumonitis. Clin Allergy Immunol. 2002;16:449-468.

25. Noth I, Strek ME, Leff AR. Churg - Strauss syndrome. Lancet. 2003; 361(9357):587-594.

26. Goldman J, Muers M. Vocal cord dysfunction and wheezing. Thorax. 1991;46(6):401-404.

27. Wood RP 2nd, Milgrom H. Vocal cord dysfunction. J Allergy Clin Immunol. 1996;98(3):481-485.

28. Heaney LG, Conway E, Kelly C, et al. Predictors of therapy resistant asthma: outcome of a systematic evaluation protocol. Thorax. 2003; 58(7):561-566.

29. ten Brinke A, Grootendorst DC, Schmidt JT, et al. Chronic sinusitis in severe asthma is related to sputum eosinophilia. JAllergy Clin Immunol. 2002;109(4):621-626.

30. Bresciani M, Paradis L, Des Roches A, et al. Rhinosinusitis in severe asthma. J Allergy Clin Immunol. 2001;107(1):73-80.

31. Mascia K, Haselkorn T, Deniz YM, Miller DP, Bleecker ER, Borish L. Aspirin sensitivity and severity of asthma: evidence for irreversible airway obstruction in patients with severe or difficult-to-treat asthma. J Allergy Clin Immunol. 2005;116(5):970-975.

32. Corren J. Allergic rhinitis and asthma: how important is the link? J Allergy Clin Immunol. 1997;99(2):S781-S786.

33. Ceylan E, Gencer M, San I. Nasal polyps and the severity of asthma. Respirology. 2007;12(2):272-276.

34. Field SK, Underwood M, Brant R, Cowie RL. Prevalence of gastroesophageal reflux symptoms in asthma. Chest. 1996;109(2):316-322.

35. Littner MR, Leung FW, Ballard ED 2nd, Huang B, Samra NK. Effects of 24 weeks of lansoprazole therapy on asthma symptoms, exacerbations, quality of life, and pulmonary function in adult asthmatic patients with acid reflux symptoms. Chest. 2005;128(3):1128-1135.

36. Kiljander TO, Harding SM, Field SK, et al. Effects of esomeprazole $40 \mathrm{mg}$ twice daily on asthma: a randomized placebo-controlled trial. Am J Respir Crit Care Med. 2006;173(10):1091-1097.

37. Leggett JJ, Johnston BT, Mills M, Gamble J, Heaney LG. Prevalence of gastroesophageal reflux in difficult asthma: relationship to asthma outcome. Chest. 2005;127(4):1227-1231.

38. Mastronarde JG, Anthonisen NR, Castro M, et al. Efficacy of esomeprazole for treatment of poorly controlled asthma. N Engl J Med. 2009; 360(15):1487-1499.

39. Collins JE, Gill TK, Chittleborough CR, Martin AJ, Taylor AW, Winefield H. Mental, emotional, and social problems among school children with asthma. J Asthma. 2008;45(6):489-493.

40. Miles JF, Garden GM, Tunnicliffe WS, Cayton RM, Ayres JG. Psychological morbidity and coping skills in patients with brittle and non-brittle asthma: a case-control study. Clin Exp Allergy. 1997;27(10):1151-1159.

41. Roy-Byrne PP, Davidson KW, Kessler RC, et al. Anxiety disorders and comorbid medical illness. Gen Hosp Psychiatry. 2008;30(3):208-225.

42. Kullowatz A, Rosenfield D, Dahme B, Magnussen H, Kanniess F, Ritz T. Stress effects on lung function in asthma are mediated by changes in airway inflammation. Psychosom Med. 2008;70(4):468-475.

43. Lange P, Parner J, Vestbo J, Schnohr P, Jensen G. A 15-year follow-up study of ventilatory function in adults with asthma. N Engl J Med. 1998; 339(17):1194-1200.

44. Eisner MD, Iribarren C. The influence of cigarette smoking on adult asthma outcomes. Nicotine Tob Res. 2007;9(1):53-56.

45. Marquette $\mathrm{CH}$, Saulnier F, Leroy O, et al. Long-term prognosis of nearfatal asthma. A 6-year follow-up study of 145 asthmatic patients who underwent mechanical ventilation for a near-fatal attack of asthma. Am Rev Respir Dis. 1992;146(1):76-81.

46. Chaudhuri R, Livingston E, McMahon AD, Thomson L, Borland W, Thomson NC. Cigarette smoking impairs the therapeutic response to oral corticosteroids in chronic asthma. Am J Respir Crit Care Med. 20031;168(11):1308-1311.

47. Tomlinson JE, McMahon AD, Chaudhuri R, Thompson JM, Wood SF, Thomson NC. Efficacy of low and high dose inhaled corticosteroid in smokers versus non-smokers with mild asthma. Thorax. 2005;60(4):282-287.
48. Polosa R, Knoke JD, Russo C, et al. Cigarette smoking is associated with a greater risk of incident asthma in allergic rhinitis. J Allergy Clin Immunol. 2008;121(6):1428-1434.

49. Currie GP, Jackson CM, Lee DK, Lipworth BJ. Allergen sensitization and bronchial hyper-responsiveness to adenosine monophosphate in asthmatic patients. Clin Exp Allergy. 2003;33(10):1405-1408.

50. Le Moual N, Siroux V, Pin I, Kauffmann F, Kennedy SM. Asthma severity and exposure to occupational asthmogens. Am J Respir Crit Care Med. 2005;172(4):440-445.

51. Sin DD, Sutherland ER. Obesity and the lung: 4. Obesity and asthma. Thorax. 2008;63(11):1018-1023.

52. van Veen IH, ten Brinke A, Sterk PJ, Rabe KF, Bel EH. Airway inflammation in obese and nonobese patients with difficult-to-treat asthma. Allergy. 2008;63(5):570-574.

53. Camargo CA Jr, Weiss ST, Zhang S, Willett WC, Speizer FE. Prospective study of body mass index, weight change, and risk of adult-onset asthma in women. Arch Intern Med. 1999;159(21):2582-2588.

54. Hakala K, Stenius-Aarniala B, Sovijarvi A. Effects of weight loss on peak flow variability, airways obstruction, and lung volumes in obese patients with asthma. Chest. 2000;118(5):1315-1321.

55. Stenius-Aarniala B, Poussa T, Kvarnstrom J, Gronlund EL, Ylikahri M, Mustajoki P. Immediate and long term effects of weight reduction in obese people with asthma: randomised controlled study. $B M J$. 2000;320(7238):827-832.

56. http://www.fp7-consulting.be/en/ubiopred/. 2008.

57. Wenzel SE, Schwartz LB, Langmack EL, et al. Evidence that severe asthma can be divided pathologically into two inflammatory subtypes with distinct physiologic and clinical characteristics. Am J Respir Crit Care Med. 1999;160(3):1001-1008.

58. Ito K, Chung KF, Adcock IM. Update on glucocorticoid action and resistance. J Allergy Clin Immunol. 2006;117(3):522-543.

59. Roberts NJ, Robinson DS, Partridge MR. How is difficult asthma managed? Eur Respir J. 2006;28(5):968-973.

60. Noonan M, Chervinsky P, Busse WW, et al. Fluticasone propionate reduces oral prednisone use while it improves asthma control and quality of life. Am J Respir Crit Care Med. 1995;152(5 Pt 1):1467-1473.

61. Gibson PG, Powell H, Ducharme F. Long-acting beta2-agonists as an inhaled corticosteroid-sparing agent for chronic asthma in adults and children. Cochrane Database Syst Rev. 2005;(4):CD005076.

62. Nightingale JA, Rogers DF, Barnes PJ. Comparison of the effects of salmeterol and formoterol in patients with severe asthma. Chest. 2002; 21(5):1401-1406.

63. Guyer B, Gibbs R, Feldsien D, Wenzel S. A pilot study to evaluate the bronchodilator response pattern to salmeterol in refractory asthma. J Allergy Clin Immunol. 2002:109(S244).

64. Tonelli M, Zingoni M, Bacci E, et al. Short-term effect of the addition of leukotriene receptor antagonists to the current therapy in severe asthmatics. Pulm Pharmacol Ther. 2003;16(4):237-240.

65. Rodrigo GJ, Rodrigo C. Triple inhaled drug protocol for the treatment of acute severe asthma. Chest. 2003;123(6):1908-1915.

66. Virchow JC, Lommatzch M editors. Anticholinergic agents in asthma. Oxford: Clinical Publishing, 2007.

67. Vatrella A, Ponticiello A, Pelaia G, Parrella R, Cazzola M. Bronchodilating effects of salmeterol, theophylline and their combination in patients with moderate to severe asthma. Pulm Pharmacol Ther. 2005;18(2):89-92.

68. Roberts G, Newsom D, Gomez K, et al. Intravenous salbutamol bolus compared with an aminophylline infusion in children with severe asthma: a randomised controlled trial. Thorax. 2003;58(4):306-310.

69. Silverman RA, Osborn H, Runge J, et al. IV magnesium sulfate in the treatment of acute severe asthma: a multicenter randomized controlled trial. Chest. 2002;122(2):489-497.

70. Beasley R, Aldington S. Magnesium in the treatment of asthma. Curr Opin Allergy Clin Immunol. 2007;7(1):107-110.

71. Mortimer KJ, Tattersfield AE. Benefit versus risk for oral, inhaled, and nasal glucocorticosteroids. Immunol Allergy Clin North Am. 2005; 25(3):523-539. 
72. Keenan GF. Management of complications of glucocorticoid therapy. Clin Chest Med. 1997;18(3):507-520.

73. Joseph A, Brasington R, Kahl L, Ranganathan P, Cheng TP, Atkinson J. Immunologic rheumatic disorders. JAllergy Clin Immunol. 125(2 Supp12): S204-S215.

74. Comet R, Domingo C, Larrosa M, et al. Benefits of low weekly doses of methotrexate in steroid-dependent asthmatic patients. A doubleblind, randomized, placebo-controlled study. Respir Med. 2006;100(3): 411-419.

75. Hedman J, Seideman P, Albertioni F, Stenius-Aarniala B. Controlled trial of methotrexate in patients with severe chronic asthma. Eur J Clin Pharmacol. 1996;49(5):347-349.

76. Trigg CJ, Davies RJ. Comparison of methotrexate $30 \mathrm{mg}$ per week with placebo in chronic steroid-dependent asthma: a 12-week double-blind, cross-over study. Respir Med. 1993;87(3):211-216.

77. Mullarkey MF, Lammert JK, Blumenstein BA. Long-term methotrexate treatment in corticosteroid-dependent asthma. Ann Intern Med. 1990; 112(8):577-581

78. Shiner RJ, Katz I, Shulimzon T, Silkoff P, Benzaray S. Methotrexate in steroid-dependent asthma: long-term results. Allergy. 1994;49(7): $565-568$.

79. Domingo C, Moreno A, Amengual MJ, Comet R, Lujan M. Twelve years' experience with methotrexate for GINA treatment step 5 asthma patients. Curr Med Res Opin. 2009;25(2):367-374.

80. Aaron SD, Dales RE, Pham B. Management of steroid-dependent asthma with methotrexate: a meta-analysis of randomized clinical trials. Respir Med. 1998;92(8):1059-1065.

81. Davies H, Olson L, Gibson P. Methotrexate as a steroid sparing agent for asthma in adults. Cochrane Database Syst Rev. 2000(2):CD000391.

82. Marin MG. Low-dose methotrexate spares steroid usage in steroid-dependent asthmatic patients: a meta-analysis. Chest. 1997;112(1):29-33.

83. Corrigan CJ, Kay AB. T cells and eosinophils in the pathogenesis of asthma. Immunol Today. 1992;13(12):501-507.

84. Fukuda T, Asakawa J, Motojima S, Makino S. Cyclosporine A reduces $\mathrm{T}$ lymphocyte activity and improves airway hyperresponsiveness in corticosteroid-dependent chronic severe asthma. Ann Allergy Asthma Immunol. 1995;75(1):65-72.

85. Khan LN, Kon OM, Macfarlane AJ, et al. Attenuation of the allergeninduced late asthmatic reaction by cyclosporin $\mathrm{A}$ is associated with inhibition of bronchial eosinophils, interleukin-5, granulocyte macrophage colony-stimulating factor, and eotaxin. Am J Respir Crit Care Med. 2000;162(4 Pt 1):1377-1382.

86. Sihra BS, Kon OM, Durham SR, Walker S, Barnes NC, Kay AB Effect of cyclosporin $A$ on the allergen-induced late asthmatic reaction. Thorax. 1997;52(5):447-452.

87. Lock SH, Kay AB, Barnes NC. Double-blind, placebo-controlled study of cyclosporin A as a corticosteroid-sparing agent in corticosteroiddependent asthma. Am J Respir Crit Care Med. 1996;153(2):509-514.

88. Nizankowska E, Soja J, Pinis G, et al. Treatment of steroid-dependent bronchial asthma with cyclosporin. Eur Respir J. 1995;8(7):1091-1099.

89. Alexander AG, Barnes NC, Kay AB. Trial of cyclosporin in corticosteroid-dependent chronic severe asthma. Lancet. 1992;39(8789): 324-328.

90. Nizankowska E, Dworski R, Szczeklik A. Cyclosporin for a severe case of aspirin-induced asthma. Eur Respir J. 1991;4(3):380.

91. Szczeklik A, Nizankowska E, Dworski R, Domagala B, Pinis G. Cyclosporin for steroid-dependent asthma. Allergy. 1991;46(4):312-315

92. Evans DJ, Cullinan P, Geddes DM. Cyclosporin as an oral corticosteroid sparing agent in stable asthma. Cochrane Database Syst Rev. 2001;(2):CD002993.

93. Dougados M, Awada H, Amor B. Cyclosporin in rheumatoid arthritis: a double blind, placebo controlled study in 52 patients. Ann Rheum Dis 1988;47(2):127-133.

94. Kornbluth A, Present DH, Lichtiger S, Hanauer S. Cyclosporin for severe ulcerative colitis: a user's guide. Am J Gastroenterol. 1997;92(9): 1424-1428.
95. Spector SL, Katz FH, Farr RS. Troleandromycin: effectiveness in steroid-dependent asthma and bronchitis. J Allergy Clin Immunol. 1974;54(6):367-379.

96. Szefler SJ, Rose JQ, Ellis EF, Spector SL, Green AW, Jusko WJ. The effect of troleandomycin on methylprednisolone elimination. J Allergy Clin Immunol. 1980;66(6):447-451.

97. Black PN, Blasi F, Jenkins CR, et al. Trial of roxithromycin in subjects with asthma and serological evidence of infection with Chlamydia pneumoniae. Am J Respir Crit Care Med. 2001;164(4):536-541.

98. Johnston SL, Blasi F, Black PN, Martin RJ, Farrell DJ, Nieman RB. The effect of telithromycin in acute exacerbations of asthma. $N$ Engl $J$ Med. 2006;354(15):1589-1600.

99. Ball BD, Hill MR, Brenner M, Sanks R, Szefler SJ. Effect of lowdose troleandomycin on glucocorticoid pharmacokinetics and airway hyperresponsiveness in severely asthmatic children. Ann Allergy. 1990; 65(1):37-45.

100. Kamada AK, Hill MR, Ikle DN, Brenner AM, Szefler SJ. Efficacy and safety of low-dose troleandomycin therapy in children with severe, steroid-requiring asthma. J Allergy Clin Immunol. 1993;91(4):873-882.

101. Nelson HS, Hamilos DL, Corsello PR, Levesque NV, Buchmeier AD, Bucher BL. A double-blind study of troleandomycin and methylprednisolone in asthmatic subjects who require daily corticosteroids. $\mathrm{Am}$ Rev Respir Dis. 1993;147(2):398-404.

102. Garey KW, Rubinstein I, Gotfried MH, Khan IJ, Varma S, Danziger LH. Long-term clarithromycin decreases prednisone requirements in elderly patients with prednisone-dependent asthma. Chest. 2000;118(6):1826-1827.

103. Gotfried MH, Jung R, Messick C, et al. Effects of Six-Week Clarithromycin Therapy in Corticosteroid-Dependent Asthma: A Randomized Double-Blind, Placebo-Controlled Pilot Study. Curr Ther Res Clin Exp. 2004;65(1):1-12.

104. Simpson JL, Powell H, Boyle MJ, Scott RJ, Gibson PG. Clarithromycin targets neutrophilic airway inflammation in refractory asthma. Am J Respir Crit Care Med. 2008;177(2):148-155.

105. Omalizumab for persistent allergic asthma. In: Excellence NIoC, editor. London: NICE technology appraisal guidance; 2007:133.

106. Gould HJ, Sutton BJ. IgE in allergy and asthma today. Nat Rev Immunol. 2008;8(3):205-217.

107. Presta L, Shields R, O'Connell L, et al. The binding site on human immunoglobulin E for its high affinity receptor. J Biol Chem. 1994; 269(42):26368-26373.

108. Shields RL, Whether WR, Zioncheck K, et al. Inhibition of allergic reactions with antibodies to IgE. Int Arch Allergy Immunol. 1995; 107(1-3):308-312.

109. Boulet LP, Chapman KR, Cote J, et al. Inhibitory effects of an antiIgE antibody E25 on allergen-induced early asthmatic response. $\mathrm{Am}$ J Respir Crit Care Med. 1997;155(6):1835-1840.

110. Fahy JV, Fleming HE, Wong HH, et al. The effect of an anti-IgE monoclonal antibody on the early- and late-phase responses to allergen inhalation in asthmatic subjects. Am J Respir Crit Care Med. 1997; 155(6): 1828-1834.

111. Walker S, Monteil M, Phelan K, Lasserson TJ, Walters EH. Anti-IgE for chronic asthma in adults and children. Cochrane Database Syst Rev. 2006(2):CD003559.

112. Bousquet J, Cabrera P, Berkman N, et al. The effect of treatment with omalizumab, an anti-IgE antibody, on asthma exacerbations and emergency medical visits in patients with severe persistent asthma. Allergy. 2005;60(3):302-308.

113. Bousquet J, Wenzel S, Holgate S, Lumry W, Freeman P, Fox H. Predicting response to omalizumab, an anti-IgE antibody, in patients with allergic asthma. Chest. 2004;125(4):1378-1386.

114. Chipps B, Corren J, Finn A, Hedgecock S, Fox H, Blogg M. Omalizumab significantly improves quality of life in patients with severe persistent asthma. J Allergy Clin Immunol. 2005;115(2):S5-S19.

115. Finn A, Gross G, van Bavel J, et al. Omalizumab improves asthmarelated quality of life in patients with severe allergic asthma. JAllergy Clin Immunol. 2003;111(2):278-284. 
116. Vignola AM, Humbert M, Bousquet J, et al. Efficacy and tolerability of anti-immunoglobulin E therapy with omalizumab in patients with concomitant allergic asthma and persistent allergic rhinitis: SOLAR. Allergy. 2004;59(7):709-717.

117. Cruz AA, Lima F, Sarinho E, et al. Safety of anti-immunoglobulin E therapy with omalizumab in allergic patients at risk of geohelminth infection. Clin Exp Allergy. 2007;37(2):197-207.

118. Cazzola M, Polosa R. Anti-TNF-alpha and Th1 cytokine-directed therapies for the treatment of asthma. Curr Opin Allergy Clin Immunol. 2006;6(1):43-50.

119. Morjaria JB, Babu KS, Holgate ST, Polosa R. Tumour necrosis factor alpha as a therapeutic target in asthma. Drug Discov Today Ther Strateg. 2006;3(3):309-316.

120. Feldmann M, Maini R; for Lasker Clinical Medical Research Award. TNF defined as a therapeutic target for rheumatoid arthritis and other autoimmune diseases. Nat Med. 2003;9:1245-1250.

121. Erin EM, Leaker BR, Nicholson GC, et al. The effects of a monoclonal antibody directed against tumour necrosis factor-\{alpha\} (TNF\{alpha\}) in asthma. Am J Respir Crit Care Med. 2006.

122. Rouhani FN, Meitin CA, Kaler M, Miskinis-Hilligoss D, Stylianou M, Levine SJ. Effect of tumor necrosis factor antagonism on allergenmediated asthmatic airway inflammation. Respir Med. 2005;99(9): 1175-1182.

123. Berry MA, Hargadon B, Shelley M, et al. Evidence of a role of tumor necrosis factor alpha in refractory asthma. $N$ Engl J Med. 2006; 354(7):697-708.

124. Howarth PH, Babu KS, Arshad HS, et al. Tumour Necrosis Factor (TNF $\{$ alpha $\}$ ) as a novel therapeutic target in symptomatic corticosteroid-dependent asthma. Thorax. 2005.

125. Morjaria JB, Chauhan AJ, Babu KS, Polosa R, Davies DE, Holgate ST. The role of a soluble TNF-A receptor fusion protein (Etanercept) in corticosteroid-refractory asthma: a double blind, randomised placebocontrolled trial. Thorax. 2008.

126. Wenzel SE, Barnes PJ, Bleecker ER, et al. A randomized, doubleblind, placebo-controlled study of tumor necrosis factor-alpha blockade in severe persistent asthma. Am J Respir Crit Care Med. 2009; 179(7):549-558.

127. Bongartz T, Sutton AJ, Sweeting MJ, Buchan I, Matteson EL, Montori V. Anti-TNF antibody therapy in rheumatoid arthritis and the risk of serious infections and malignancies: systematic review and meta-analysis of rare harmful effects in randomized controlled trials. JAMA. 2006;295(19):2275-2285.

128. Desai D, Brightling C. Cytokine and anti-cytokine therapy in asthma: ready for the clinic? Clin Exp Immunol. 2009;158(1):10-19.

129. Leckie MJ, ten BrinkeA, Khan J, et al. Effects of an interleukin-5 blocking monoclonal antibody on eosinophils, airway hyper-responsiveness, and the late asthmatic response. Lancet. 2000;356(9248): 2144-2148.

130. Flood-Page PT, Menzies-Gow AN, Kay AB, Robinson DS. Eosinophil's role remains uncertain as anti-interleukin-5 only partially depletes numbers in asthmatic airway. Am J Respir Crit Care Med. 2003;167(2): 199-204.

131. Flood-Page P, Swenson C, Faiferman I, et al. A study to evaluate safety and efficacy of mepolizumab in patients with moderate persistent asthma. Am J Respir Crit Care Med. 2007;176(11):1062-1071.
132. Kips JC, O'Connor BJ, Langley SJ, etal. Effect of SCH55700, a humanized anti-human interleukin-5 antibody, in severe persistent asthma: a pilot study. Am J Respir Crit Care Med. 2003;167(12): 1655-1659.

133. Flood-Page P, Menzies-Gow A, Phipps S, et al. Anti-IL-5 treatment reduces deposition of ECM proteins in the bronchial subepithelial basement membrane of mild atopic asthmatics. J Clin Invest. 2003;112(7):1029-1036.

134. Haldar P, Brightling CE, Hargadon B, et al. Mepolizumab and exacerbations of refractory eosinophilic asthma. N Engl J Med. 2009; 360(10):973-984.

135. Nair P, Pizzichini MM, Kjarsgaard M, et al. Mepolizumab for prednisone-dependent asthma with sputum eosinophilia. $N$ Engl J Med. 2009;360(10):985-993.

136. Azzawi M, Johnston PW, Majumdar S, Kay AB, Jeffery PK. T lymphocytes and activated eosinophils in airway mucosa in fatal asthma and cystic fibrosis. Am Rev Respir Dis. 1992;145(6):1477-1482.

137. Park CS, Lee SM, Chung SW, Uh S, Kim HT, Kim YH. Interleukin-2 and soluble interleukin-2 receptor in bronchoalveolar lavage fluid from patients with bronchial asthma. Chest. 1994;106(2):400-406.

138. Kon OM, Kay AB. Anti-T cell strategies in asthma. Inflamm Res. 1999;48(10):516-523.

139. Robinson DS, Bentley AM, Hartnell A, Kay AB, Durham SR. Activated memory $\mathrm{T}$ helper cells in bronchoalveolar lavage fluid from patients with atopic asthma: relation to asthma symptoms, lung function, and bronchial responsiveness. Thorax. 1993;48(1):26-32.

140. Busse WW, Israel E, Nelson HS, et al. Daclizumab improves asthma control in patients with moderate to severe persistent asthma: a randomized, controlled trial. Am J Respir Crit Care Med. 2008;178(10):1002-1008.

141. Woodruff PG, Dolganov GM, Ferrando RE, et al. Hyperplasia of smooth muscle in mild to moderate asthma without changes in cell size or gene expression. Am J Respir Crit Care Med. 2004;169(9):1001-1006.

142. Carroll N, Elliot J, Morton A, James A. The structure of large and small airways in nonfatal and fatal asthma. Am Rev Respir Dis. $1993 ; 147(2): 405-410$.

143. Danek CJ, Lombard CM, Dungworth DL, et al. Reduction in airway hyperresponsiveness to methacholine by the application of RF energy in dogs. J Appl Physiol. 2004;97(5):1946-1953.

144. Miller JD, Cox G, Vincic L, Lombard CM, Loomas BE, Danek CJ. A prospective feasibility study of bronchial thermoplasty in the human airway. Chest. 2005;127(6):1999-2006.

145. Cox G, Miller JD, McWilliams A, Fitzgerald JM, Lam S. Bronchial thermoplasty for asthma. Am J Respir Crit Care Med. 2006;173(9): 965-969.

146. Cox G, Thomson NC, Rubin AS, et al. Asthma control during the year after bronchial thermoplasty. $N$ Engl J Med. 2007;356(13): 1327-1337.

147. Pavord ID, Cox G, Thomson NC, et al. Safety and efficacy of bronchial thermoplasty in symptomatic, severe asthma. Am J Respir Crit Care Med. 2007;176(12):1185-1191.

148. Castro M, Rubin AS, Laviolette M, et al. Effectiveness and safety of bronchial thermoplasty in the treatment of severe asthma: a multicenter, randomized, double-blind, sham-controlled clinical trial. Am J Respir Crit Care Med. 181(2):116-124.
Journal of Asthma and Allergy

\section{Publish your work in this journal}

The Journal of Asthma and Allergy is an international, peer-reviewed open-access journal publishing original research, reports, editorials and commentaries on the following topics: Asthma; Pulmonary physiology; Asthma related clinical health; Clinical immunology and the immunological basis of disease; Pharmacological interventions and

new therapies. Issues of patient safety and quality of care will also be considered. The manuscript management system is completely online and includes a very quick and fair peer-review system, which is all easy to use. Visit http://www.dovepress.com/testimonials.php to read real quotes from published authors.

\section{Dovepress}

Submit your manuscript here: http://www.dovepress.com/journal-of-asthma-and-allergy-journal 